DE82 010865

\title{
Emanation of Tritiated Water from Disposal Sites at Los Alamos, New Mexico
}

W. V. Abeele

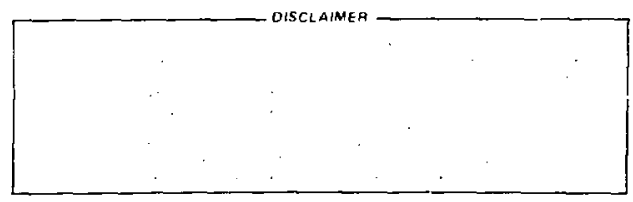




\title{
EMANATION OF TRITIATED WATER FROM DISPOSAL SITES \\ AT LOS ALAMOS, NEW MEXICO
}

by

\author{
W. V. Abeele
}

\begin{abstract}
The level of contamination induced by the presence of tritiated water (HTO) un the Bandelier tuff near Los Alanos, New Mexico has been seen to decrease vertically and horizontally the same rate. This decrease in radioactivity with distance from the source has been measured around three different disposal shafts and found to be scinewhat slower than the decrease in emanation rate with distance from the source.

Physical factors, suspected of influencing HTO emanation, were entered as independent variables in a regression equation including measurements taken over a 14 month period. The physical variables studied were of thermal, hydrological, and meteoroiogical origin or a combination of the above. Only four variables were retaine $f$ as significant although they explained only $71 \%$ of the variation in HTO flux.
\end{abstract}

\section{INTRODUCTION}

Determining the potential impact of buried radioactive wastes on the environment requires knowledge of the rates at which the radionuclides can enter the environment. These rates may differ both as a function of distance from the source and physical factors affecting their release. Tritiated water (HTO) emanation is expected to be a function of spatial distribution and, at the same time, subject to the influence of pertinent meteorological and pedological variables. Fourteen of these have been considered in this study.

\section{A. Tritiated Water in Soils}

Radionuclides disposed of at the Los Alamos National Laboratory include significant amounts of transuranics (mostly plutonium and amencium), uranium, fission products, activason products, and tritium. All investigations of the radioactive waste disposal areas revealed that, with the excepiion of tritium, no migration of these radionuclides has been detectable. Because of the high mobility of tritium in biological systems, there is a legitimate need to define and minimize the quantities of this radionuclide entering the environment from disposal areas (Wheeler et al., 1975). Migration of tritium from its disposal site was detected as early as 1970 , although dissolution and subseouent migration of solid radionuclides in the disposal area is minimal. This hias been verified continually by analysis of innumerable samples collected during the excavation of additional shafts in the disposal areas. Tritium, on the other hand, occurring principally as tritiated water, is nearly as free to move as water itself. Smal! quantities of tritium gas, disposed of by burial, convert very quickly to HTO on exposure to soil oxygen: and moisture. 
Before mid-1958, all tritium-containing wastes were disposed of by burial with other wastes in disposal pits. Since that time and until November 1973 , unined shafts, 8 to $20 \mathrm{~m}$ deep by 0.6 - to 1.8 -m diam, were used. Since November 1973, the walls and botton of the disposal shafts for tritium wastes have been coated with a 1- to 2-cm layer of asphalt in an attempt to seal the many fractures in the tuff walls of the shaft, because it was believed that such fractures provideil possible pathways for tritium migration (Wheeler et al., 1975). A study had previously shown that unlined tritium shafts were significant sources of soil contam nation (Purtymun, 1973). In that study it is shown that around an unlined shaft (number 13. Area G, I'echnical Area 54 on Mesita del Buey), tritium concentration in the surrounding tuff increased to a maximum between depths of 3 to $10 \mathrm{~m}$ and then decreased again with depth. Irregularities in the isotritium contours are seemingly influenced by the presence of open joints in the tuff. which provide for a much more rapid means of migration in the vapor phase. Close but irregular isotritium contours or high tritjum gradients are to be found between the source (shaft) and an eventual transversa) joint. The contours are elongated to the west of the shaft, indicating regions where either a radial joint was present or the outward (upward) movement of tritium was inhibited. High tritium gradients would consequently be an indication of swift, uninhibited aeration of tritium. A close and complete set of isotritium contour lines, which deserved close scrutiny, has been chosen along a southwest axis. The presence of tritium radioactivity decreases logarithmically with distance from the shaft. Table I indicates the rate of decrease at various deoths of radioactivity as a function of disiance from the shaft. There were as many as seven contour lines intersecting the southwest axis. The radioactivity is measured in Becquerels per cubic meter of water and is deternined by the Liquid Scintillation Counter Method. Most interestingly, $:$ vertical plane along the shaft axis showed that the maximum tritum concentration was located near the bottom of the shaft with the radioactivity decreasing upward according to $A=1.11 \cdot 10^{11}$ $-6 \cdot 10^{9}$ lnd and $\mathrm{r}=0.97$. The similarity between the rate of decrease in radioactivity as a function of distance is striking along the vertical and horizontal planes! The closest match is between the horizonta! rate of decrease as a function of distance from the shaft at $6.75-\mathrm{m}$ depth and the vertical rate of decreasc upward as a function of distance from the bottom of the shaft.

Shafts 50 and 59, also located in Area G. Technical Area 54 on the Mesita del Buey. have received tritium contaminated waste since 1973. Approximately the same time period elapsed between the placement of the waste and the collection of samples in shafts 50 and 59 as in shaft 13 . Both shafts 50 and 59 were asphalt lined and asphalt containment was applied to the packaging of wastes placed in the shafts. Yet, on a percentage basis, significantly more tritium has migrated out of shafts where asphalt containment was used than from shafts where no asphalt was applied. Undoubtedly many factors mntribute to this difference, including ditisent waste forms and packaging before asphalting, variabiluties in permeability of the tuff, and differences in the size and number of fractures intersected by the various shafts. However, the asphalting was intended to counteract and override these variabilities. It is

\section{TABLE I}

\section{DECREASE IN RADIOACTIVITY NEAR SHAFT 13 AS A FUNCTION OF DISTANCE FROM THE SHAFT, ALONG A S-W AXIS}

\begin{tabular}{|c|c|c|}
\hline Depth $(m)$ & $\begin{array}{c}\text { Rate of Decrease } \\
\left(B q \mathrm{~m}^{-3}\right)\end{array}$ & $\begin{array}{c}\text { Coefficient } \\
\text { of Correlation }\end{array}$ \\
\hline 3.75 & $A=3.1 \cdot 10^{9} \cdot 1.01 \cdot 10^{9} \operatorname{lnd}$ & $r=0.96$ \\
\hline 6.75 & $A=1.24 \cdot 10^{10} \cdot 5.27 \cdot 10^{9}$ Ind & $r=0.97$ \\
\hline 9.75 & $A=2.87 \cdot 10^{9}-1.0410^{9}$ lnd & $\mathbf{r}=0.98$ \\
\hline 12.75 & $A=1.23 \cdot 10^{9} \cdot 5.2810^{8}$ lnd & $r=0.96$ \\
\hline
\end{tabular}


concluded that the asphalting techniques, as applied in the past, did not significantly reduce the migration of tritium away from the disposal shafts. The shafts also appear to serve as a moisture source to the tuff, particularly at depth (Wheeler et al. 1975). This is probably because of the entrance of precipitation into the shafts during and between waste deliveries and before they are sealed. The asphalted bottom serves as an inhibitor to the flow of moisture out of the shaft, and this moisture in turn increases the total amount of water vapor to be diffused out of the shaft after its closure.

In this case also, tritium activity decreases logarithmically with distance from the shaft. Table II indicates, at two different depths, the rate of decrease of radioactivity as a function of distance from shafts 50 and 59 . The fastest rate of decrease away from shaft 50 is along a SSW axis, although it seems fastest along the eastern axis originating at shaft 59 . However, the tritium data are incomplete along the eastern axis, so that the next steepest gradient, along the northern axis, was chosen for analysis. For the tuff surrounding shafts 50 and 59 , the radioactivity was measured using as basis a unit volume of tuff instead of water, as was used for the analy ses surrounding shaft 13. Based on this fact, the constants in the regression equation should be higher for shaft 13 for equal degrees of contamination. Because this is barely the case, it can be concluded that tritium contamination is substantially higher arnund shafts 50 and 59. The rates of decrease as a function of distance from the shaft are strikingly similar in both cases!

Because the preceding studies revealed that the asphalt was not significantly retarding tritium migration away from disposal shafts. a decision was made by the Waste Management Operations Group $(\mathrm{H}-7)$ to implement more rigorous packaging procedures involving the use of asphalt for tritium containing wastes. Asphalt coating of the shaft itself was eliminated.

To test the effectiveness of the new procedures. the new disposal shaft. No. 150, was located in an area where no prior tritium disposals had occurred. The extent of tritium migration into the tuff surrounding the shaft could then be related directly to the contents of the shaft. Disposal shaft 150 was drilled in the spring of 1976, with the first disposal occurring on 12 May 1976. In the winter of 1977, after more than $1.10^{19} \mathrm{~Bq}$ of tritium had been disposed to the shaft, nine sampling holes were augered around the shaft. The samples were processed to remove the contained water, and the water was analyzed for tritium. The sampling holes were provided with surface casings and then sealed. Subsequently, in the fall of 1979 , samples of the water vapor in the access holes were collected using silica gel as an absorbing medium. Water was distilled from the gel and analyzed for tritium. Also, the moisture content of the tuff surrounding the access holes was determined using a neutron moisture probe. The average water content in the tuff surrounding the shaft was about $4 \%$ by volume. This value agrees well with other measurements made in the area.

This latest study shows a release of 0.5 to $0.7 \%$ of the tritium in the shaft to the surrounding tuff ys an estimated 0.3 to $0.6 \%$ in the two previous cases. Thus, no improvement in tritium containment was obtained by the new procedures. It is difficult to establish whether the packaging grocedures themselves were inadequate. or the quality control on the procedures was inadequate.

\section{TABLE II}

\section{DECREASE IN RADIOACTIVITY NEAR SHAFTS 50 AND 59 AS A FUNCTION OF DISTANCE FROM THE SHAFT}

\begin{tabular}{|c|c|c|c|c|}
\hline Shaft & Axis & Depth $(m)$ & $\begin{array}{l}\text { Rate of Decrease } \\
\left(\mathrm{Bq} \mathrm{m}^{-3}\right)\end{array}$ & $\begin{array}{c}\text { Coefficient } \\
\text { of Correlation }\end{array}$ \\
\hline 50 & SSW & 3.75 & $\mathbf{A}=1.01 \cdot 10^{9}-6.09 \cdot 10^{8}$ Ind & $r=0.98$ \\
\hline 50 & SSW & 6.75 & $A=1.21 \cdot 10^{9}-5.61 \cdot 10^{8}$ lnd & $r=0.94$ \\
\hline 59 & $\mathbf{N}$ & 3.75 & $A==1.03 \cdot 10^{9}-6.06 \cdot 10^{8}$ lnd & $r=0.96$ \\
\hline 59 & $N$ & 6.75 & $A=1.18 \cdot 10^{9}-5.73 \cdot 10^{8}$ lnd & $r=0.96$ \\
\hline
\end{tabular}


Release of tritium to the surrounding tuff is not a significant health hazard; however, as the inventory of tritium in the disposal site continues to grow, improved methods will be necessary to provide additional containment. The results of this study have led to the design of further improvements in the techniques for tritium disposal. Sealed steel liners will be coated with asphalt and placed inside vertical shafts.

\section{B. Emanation of Tritiated Water-Spatial Distributicn}

1. Burial Pit 1. Soil borings in the cover material overlying the waste from Burial Pit 1, Area G, Los Alamos National Laboratory, showed tritium concentrations increasing from $7.4 \cdot 10^{7} \mathrm{~Bq} \cdot \mathrm{m}^{-3}$ of soil moisture at $15 \mathrm{~cm}$ to $4.6 \cdot 10^{9} \mathrm{~Bq} \cdot \mathrm{m}^{-3}$ at $3.5 \mathrm{~m}$. This gradient suggested an upward diffusion of tritiated water from the waste (at a depth below $3.5 \mathrm{~m}$ ) to the surface soils. This tritiated water mixes with meteoritic soil moisture and is evaporated. Experiments were designed to quantify the tritium flux as a function of the distance from the source. Amounts of evaporated soil moisture were measured on silica gel collectors. Collection was at night, or on cloudy days, to reduce thermally induced lateral moisture fluxes. The average moisture flux and tritium flux were determined for the collection period. Measured

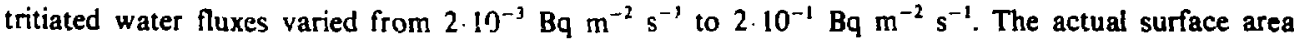
contributing to this flux was not established, but measurements of the tritium distribution in the soil suggest that orily a portion of this particular pit is contributing. Pit dimensions are approximately $30 \mathrm{~m}$ by $200 \mathrm{~m}\left(6 \cdot 10^{3} \mathrm{~m}^{2}\right)$. If the entire pit were a source at the observed rate, atmospheric releases would range from $13 \mathrm{~Bq} \mathrm{~s}^{-1}$ to $1.1 \cdot 10^{3} \mathrm{Bqs}^{-1}$ during the measurement period. Because only some fraction of the total pit is actually contributing to tritium releases, the actual tritium released is less than this amount.

2 Shafts 50-59. Two sieves filled with silica gel and covered by a heavy aluminum plate were placed at spots equidistant from shafts 50 and 59 , one at $6 \mathrm{~m}$ and the other at $10 \mathrm{~m}$ from the shafts, respectively. The activity measurements taken in February 1979 amounted to a tritiated water flux of $0.82 \mathrm{~Bq} \mathrm{~m} \mathrm{~m}^{-2} \mathrm{~s}^{-1}$ and $0.22 \mathrm{~Bq} \mathrm{~m} \mathrm{~m}^{-2} \mathrm{~s}^{-1}$, respectively.

3. Shaft GS 150. Emanation of tritiated water was measured in December 1979 along three axes, $\mathrm{A}, \mathrm{B}, \mathrm{C}, 120^{\circ}$ apart, around GS 150 . The measured average nightly concentration read $6.1 \cdot 10^{8} \mathrm{~Bq} \mathrm{\textrm {m } ^ { - 3 }}$ or soil water for an area including $113.10 \mathrm{~m}^{2}$. Because the nightly evaporation rate was averaging $7.75 \cdot 10^{\prime} \mathrm{m} \mathrm{s}^{-1}$, the total nightly release of tritiated water was $6.1 \cdot 10^{4} \mathrm{~Bq} \mathrm{~m} \mathrm{~m}^{-3} \times 7.75 \cdot 10^{-9} \mathrm{~m} \mathrm{~s}^{-1}=4.75$

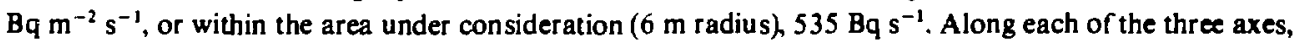
the rate of tritium emanation drops of with distance from the shaft according to a power function.

With $\mathrm{d}$, the distance, expressed in meters and $\mathrm{E}$, the tritiated water emanation, expressed in $\mathrm{Bq} \mathrm{m}^{-\mathbf{2}} \mathrm{s}^{-1}$, the regression analysis for the three different axes yields:

$$
\begin{array}{ll}
E=95.5 d^{-4.7546} & \text { with } r=0.9902 \\
E=104 d^{-4.4090} & \text { with } r=0.9972 \\
E=133 d^{-5.0313} & \text { with } r=0.9881
\end{array}
$$

The average regression analysis for the three axes yields

$$
E=110 d^{-4.7000} \quad \text { with } r=0.9932
$$

This is an indication of an extremely fast decrease of tritium release with distance from the source (GS-150). This indicates further that tritiated water vapor emanation at the soil-atmosphere interface decreases faster with distance from the source than does the tritium dispersion in the soil, where the distribution behaves as a negative $\log$ function of distance. 
In conclusion, spatial analyses point out that measurements of tritium emanation, taken in comparable locations and in the same seasonal period, yield results that form a good basis for comparison.

- Measurements taken on top of an assumed source of HTO over pit 1 average $0.2 \mathrm{~Bq} \mathrm{~m}^{-2} \mathrm{~s}^{-1}$.

- In February 1969 , at a point $6 \mathrm{~m}$ removed from both shafts 50 and 59 , a release of $0.82 \mathrm{~Bq} \mathrm{~m}^{-2} \mathrm{~s}^{-1}$ was measured.

- By the end of Decemer 1979, along the B axis originating from GS-150, the regression formula $E=$ $104 \mathrm{~d}^{4.405}$ then obtained, yielded $0.11 \mathrm{~Bq} \mathrm{~m}^{-2} \mathrm{~s}^{-1}$ at $4.7 \mathrm{~m}$ from the shaft, a result that seems to be quite compatible with actual measurements made by the end of December of the following year, when at $4.7 \mathrm{~m}$ from the shaft. the emanation was $0.14 \mathrm{~Bq} \mathrm{~m}^{-2} \mathrm{~s}^{-1}$.

Provided the rate of fall of tritium emanation with distance from the source remains the same throughout the seasons the regression equation, during the period of maximum tritium release, is expected to adopt the form $E_{\max }=9095 d^{-4.403}$. High release rates during the summer are expected because the observations follow a seasonal pattern. Atmospheric concentrations measured in 1980 are only partly influenced by soil releases (absolute humidity, wind speed, and atmospheric convection will also play an important role). Nonetheless, air concentrations also show a maximum during the warmer months and an overall minimum during the month of December. At $4.7 \mathrm{~m}$ from the shaft center (GS-150). the nightly water flux averages $7.310^{-9} \mathrm{~m} \mathrm{~s}^{-1}$, with an average HTO concentration of $2.6 \cdot 10^{8} \mathrm{~Bq} \mathrm{~m}$ m $^{-3}$. resulting in an average nightly tritiated water flux of $1.84 \mathrm{~Bq} \mathrm{m^{-2 }} \mathrm{s}^{-1}$ with a cuefficient of variation of 0.92 .

\section{PHYSICAL FACTORS INFLUENCING EMANATION}

\section{A. Pit 1}

Regressions were run between tritiated water vapor flux (as dependent variable) and various atmospheric and soil conditions at Burial Pit 1, Area G. No significant correlation could be demonstrated between atmospheric conditions and tritiated water vapor flux. The best correlation was obtained using soil moisture contents and soil moisture vapor pressures. Prior tritium disposals had occurred in the area. however, and the readings extended only over a short period of time.

\section{B. Shaft GS 150}

As mentioned previously. a new disposal shaft. No. 150 , was located in an area where no prior tritium disposals had occurred.

It has been suggested that the thermal characteristics of a medium and of the adjoining boundary layer play a role in the exhalation of the components of the vapor phase (Styra et al. 1970: Guedalia et al. 1970).

The thermal diffusivity (D) of the tuff at GS-150 was derived in situ from the measurements of daily temperature fluctuations $(\Delta T)$ at different depths $(z)$ where

$$
D=\left(-\frac{\Delta z}{\ln \left(\Delta T_{1} / \Delta T_{2}\right.}\right)^{2} \frac{\pi}{86400 s}
$$

averaged consistently $8 \cdot 10^{-1} \mathrm{~m}^{2} \mathrm{~s}^{-1}$ during an extremely dry summer period, which kept the soil moisture content low, resulting in a low specific heat by volume leading to a higher thermal diffusivity. Representative tuff debris was hauled to the laboratory, where the density was accurately established as being $1.395 \cdot 10^{3} \mathrm{~kg} \mathrm{~m}^{-3}$. 
The specific heat $\left(C_{s}\right)$ of the tuff was established in the laboratory using the standard method available for this purpose. The test was repeated four times ars averaged $C_{s} d r y=866 \mathrm{~J} \mathrm{~kg}^{-1} \mathrm{~K}^{-1}$ or a heat capacity $\mathrm{C}_{\mathrm{v}}=1.208 \cdot 10^{6} \mathrm{~J} \mathrm{~m}^{-3} \mathrm{~K}^{-1}$. Because the Moisture Ratio by Volume in situ turned out to be 0.04 . the actual heat capacity of the tuff under consideration is $C_{v 0.04}=1.375 \cdot 10^{6} \mathrm{~J} \mathrm{~m}^{-3} \mathrm{~K}^{-1}$, with a standard deviation of $2.8 \cdot 10^{4} \mathrm{~J} \mathrm{~m}^{-3} \mathrm{~K}^{-1}$. The thermal condustivity, $\gamma$, was computed to be $C_{\mathrm{v} 0.04} \mathrm{D}=1.1 \mathrm{~W} \mathrm{~m}^{-1}$ $\mathrm{K}^{-1}$.

The above characteristics will help explain the magnitudes of the temperature and consequent vapor pressure gradients in the tuff. These will be among a series of physical variables that will be studied as potential influences on tritiated water vapor emanation. To that purpose. recording thermometers and heat flow sensors were emplaced at depths of 0.10 .0 .35 . and $1.00 \mathrm{~m}$. Fourteen meteorological and pedological variables or properties were measured or computed over the period 20 May 1980 to $10 \mathrm{July}$ 1981. After preliminary screening, eight variables were retained for further analysis. Multiple Linear Regression analysis identified four independen variables as having a significant influence on HTO vapor emanation. This criterion was based on the value of lowest squared error given by Mallows (1971). More than $71 \%$ of the variation in HTO flux was associated with the regression on

- daily heat flux amplitude (in $\mathrm{Wm}_{\mathrm{m}}{ }^{2}$ ).

- meteoritic water exhalation $E$ or evaporation (in $\mathrm{ms}{ }^{1}$ ).

- maximum soil vapor pressure gradient $\mathrm{dP} / \mathrm{dx}$ (in $\mathrm{Pa} \mathrm{m}^{1}$ ). and

- atmespheric pressure variation $\Delta p$ (in $\Delta P_{a}$ ).

The independent variables are listed above in decreasing order of significance.

Because the t-test for $\Delta p$ does not exceed the tabular value at the 0.05 level for the degrees of freedom under consideration. the hypothesis that the coefficient of $\Delta p$ in the regression equation is equal to zero cannot be rejected at the $95 \%$ confidence level. This finding only adds to the controversy involving the influence of atmorpheric pressure changes on gaseous emanation from the ground. Some authors were unable to detect any direct influence of the variations in atmospheric pressure on emanation rate (Guedalia et al. 1970), whereas others suggest its effect is significant (Clements 1974).

The influence of the heat flux amplitude has been implied by Styra et al. (1970) when the maximum rate of exhalation is linked to convective streams in the soil. generated by intensive surface cooling. Emanations have also been found to be a function of seasonal variation, with little variation and lou emanation occurring during the winter months (Guedala et ai. 1970). It is worth noticing that heat flux amplitude remains extremely low in absolute value and variation during the winter months! It has also been suggested that diurnal surface heating of the soil (which is at the origin of soil heat fluxes!) may be responsible for increased transport velocities (Stvra et al. 1973).

The total nightly upward meteoritic water flux (evaporation) amounts to $0.11 \mathrm{~m} / \mathrm{yr}$. Because there is very little, if any, water seepage into deeper tuff layers. the actual evapotranspiration very closely matches the annual precipitation average of $0.46 \mathrm{~m} / \mathrm{yr}$. This tends to indicate that roughly $75 \%$ of the evaporation out of the tuff occurs during the day. Because the coefficient of aetermination $\left(r^{2}\right)$ between HTO flux and $\mathrm{H}_{2} \mathrm{O}$ flux is 0.59 , there is reason to believe that the HTO flux is likely to be about three times higher during the day time.

\section{CONCLUSIONS}

The spatial distribution of HTO in the turf and emanation at the soil-atmosphere interface show that HTO release into the atmosphere decreases faster with distance from the source than does HTO dispersion in the cuff. Lateral diffusion in the tuff may occur after a heavy rainstorm, for example, when surface pores are clogged and upward diffusion of HTO is inhibited, thus enhancing lateral distribution and entrapment of HTO. Both distributions indicate an extremely fast decrease of activity with dist ance. however. 
More than $71 \%$ of the $v$.riation in HTO flux was associated with the regression on four independent viriables. but the daily heat flux amplitude alone was accountabie for $61 \%$ of the variation. The significance of the fourth independent variable $\Delta p$ is so low, that the hypothesis assuming the coefficient of $\Delta p$ in the regression equation to be zero carinot be rejected at the $95 \%$ confidence level. This indicates that $\Delta p$ is truly of borderline significance and does nothing to settle the controversy involving the influence of atmospheric pressure cha..ges on gaseous emanation from the ground. It also indicates that most of the variables studied (10 out of 14) are quite irrelevant as far as their significance on HTO emanation is concerned.

\section{REFERENCES}

W. E. Clements. "The Effect of Atmospheric Pressure Variation on the Transport of ${ }^{221} \mathrm{Rn}$ from the Soil to the Atmosphere," submitted in partial fulfillment of the requirements for the degree of Doctor of Philosophy. New Mexico Institute of Mining and Technology. Socorro. New Merico. February 1974.

D. Guecialia, J. L. Laurent. J. Fontan. D. Blanc. and A. Druilhet. "A Study of Radon 220 Emanation from Soil.." J. Geophysical Res.. Vol. 75. No. 2. January 10. 1970.

C. L. Mallows. "Total Squared Error as a Criterion for Goodness of Fit $-\mathrm{C}_{\mathrm{p}}$ " in Fitting Equarions 10 Data. C. Daniel and F. S. Wood, Eds.. John Wiley \& Sons. Inc., New York (1971).

W. D. Purtymun. "Underground Movement of Tritium from Solid-Water Storage Shafts." Los Alamos Scientific Laboratory report LA 5286-MS (May 1973).

B. I. Styra. T. N. Nedveckaite. and E. E. Senko. "New Methods on Measuring Thoron (Radon 220) Exhalation." J. Geophysical Res.. Vol. 75. No. 18. June 20. 1970.

B. 1. Styra and T. N. Nedveckaite. "Daily Course of Radon-222 and Radon-220 Exhalation and its Application to the Irvestigation of the Aeration of Different Thickness Soil Layers Under Natural Conditions." Phy'sics of the Atmosphere I: The Circulation of Admixtures in the Atmosphere. B. I. Styra. Ed.. Institute of Physics and Mathematics of Lithuania. USSR (in Russian: English translation by M. Lang). 1973.

M. L. Whiceler and J. L. Warren: "Tritium Containment After Burial of Contaminated Solid Waste." Proceedings of 23rd Conference on Remote Systems Technology (1975). 